\title{
Educação, hegemonia e formação de dirigentes
}

Roberta Ravaglio Gagno

Professora das Faculdades Integradas Santa Cruz de Curitiba

Andréa Garcia Furtado

Professora das Faculdades Integradas Santa Cruz de Curitiba

Anita Helena Schelesener

Professora da Universidade Tuiuti do Paraná

\section{Resumo}

O objetivo deste artigo é compreender a ação da escola na qual se faz necessária a formação de lideranças que pressupõe a luta pela democratização da educação. Estas lideranças irão desempenhar funções diversificadas na sociedade, como afirma Gramsci, intelectuais, contribuindo para transformar uma concepção de mundo, de forma a assegurar a hegemonia social e o domínio estatal da classe que representam.

Palavras Chave: Educação; Dirigentes; Hegemonia.

\begin{abstract}
The aim if this paper is to understand the action of the school that is required in leadership training that involves the struggle for democratization of education. These leaders will play diverse roles in society, as Gramsci says, intellectuals, helping to transform a world view in order to ensure the social hegemony and dominance of the state class they represent.
\end{abstract}

Keywords: Education; Leadership; Hegemony. 
noção de hegemonia baseia-se no conceito político de Gramsci.
Parte-se da estrutura do modo de produção capitalista e da luta de
classes característica do período de reflexão do autor, no início do século XX. Para Gramsci, a organização de uma nova ordem social e política implica tanto a luta por mudanças estruturais quanto a formação de uma nova concepção de mundo, ou seja, para as classes trabalhadoras, a luta política é também a luta pela elaboração de uma nova cultura.

A escola, nesse sentido, deve ser compreendida sob um aspecto fundamental, como uma das instâncias em que essas divisões podem ser questionadas por meio do acesso ao saber científico e filosófico, mas essencialmente ao saber que proporcione a visão crítica e a promoção para a formação política. É um ambiente propício para o desenvolvimento e fortalecimento de uma cultura política de participação e compreensão coletiva, pois, quanto mais os indivíduos tiverem a experiência cotidiana de democracia diante do exercício de participação e de análise, mais ela terá condições para se desenvolver.

$\mathrm{Na}$ concepção liberal de sociedade, o homem é visto como um indivíduo fragmentado, isolado politicamente das reivindicações de seu grupo social, priorizando a competição, buscando uma igualdade ilusória e valorizando apenas o senso comum. Esses sujeitos tomam as concepções burguesas como as únicas verdadeiras e possíveis, separando teoria e prática e se pautando por uma mercantilização e meritocracia constantes. É por meio dessa crença que a função da escola, enquanto direito social, é desqualificada, reduzida e dualizada; nela, o cidadão é transformado em consumidor no mercado (GENTILI, 1997).

É essencial que essa postura qualificadora de princípios de justiça, liberdade e igualdade - que provém da concepção liberal - seja analisada e criticada a partir de seus limites reais. Na realidade italiana, os discursos liberais são voltados para a construção de um poder concentrado, de um Estado que é forte e governa com medidas provisórias e instrumentos de coerção, realidade mistificada pelo discurso. A questão da direção assume novos aspectos na contemporaneidade. 
Para WEFFORT (1996), não é suficiente apenas a formação de indivíduos que sejam líderes, mas de outros elementos, instituições como, por exemplo, escolas, partidos, igrejas, sindicatos, jornais... que possam auxiliar na formação desses dirigentes. Pois é por meio dessas instituições democráticas, com processos democráticos, que se formam pessoas preparadas para o trato e a perpetuação da democracia.

É necessário tornar explícita a hipótese geral que orienta nossa discussão deste ponto, ou seja, a de que os líderes bem como instituições correlatas como partidos, escolas, jornais, sindicatos, igrejas, etc. - desempenham papel relevante na condição da democracia. Primeiro as possibilidades de consolidação democrática aumentam quando líderes são democraticamente conscientes (Ibidem, p. 93).

As escolas são locais de formação que reproduzem a realidade social, cultural e econômica de uma determinada sociedade; ao mesmo tempo, podem proporcionar uma formação crítica, principalmente a partir da atuação dos seus educadores, que discutem o significado da educação no contexto real concreto, subsidiando uma sólida formação política e histórica aos estudantes. Essa educação pressupõe uma ação contínua e crítica, que parte de uma práxis coerente com o discurso adotado, de modo que a ação educativa se torna uma ação transformadora. É necessário, portanto, discutir o significado dessa educação para a realidade da vida de cada um dos indivíduos que compõem uma sociedade, pois a escola não é um ambiente neutro de significados, mas deve ser compreendida na totalidade dos fatos diante da formação de dirigentes.

Para a compreensão desses aspectos, constata-se que, a partir de Gramsci, a formação dos dirigentes e o próprio trabalho de gestão se inserem num conjunto amplo de relações de hegemonia no contexto da sociedade civil e da sociedade política. Hegemonia pode ser entendida como a formação e manutenção de formas de dominação e de direção política e cultural da sociedade, ou seja, de convencimento de um determinado conjunto da sociedade. A classe que mantém a hegemonia depende do empenho político e cultural de seus dirigentes para a formação de uma 
consciência crítica e a compreensão das relações de poder que estão inseridas no processo.

Neste texto, abordam-se alguns aspectos da relação hegemonia e dirigentes a partir da leitura de Gramsci, a fim de esclarecer o significado da função do dirigente.

Gramsci contribui com essa reflexão quando apresenta, em sua concepção, uma ampliação do conceito de Estado, formado da sociedade civil e da sociedade política numa relação dialética.

No conceito gramsciano, o Estado é concebido como um emaranhado político e ideológico, objetivando adequar as massas às necessidades do mercado, das relações de produção com o sentido de mostrar que, em todas as sociedades, essas instâncias agem entre si, mas principalmente na concepção do direito e do conformismo. Assim, sociedade civil e sociedade política se articulam e se imbricam no Estado. Quando são vistas como separadas, há possibilidade de ocultar a dominação burguesa e realizar a alternância dos grupos no poder, absorvendo a sociedade de uma forma geral e construindo uma unidade cultural, econômica e social; assim, o Estado se transforma no que GRAMSCI (1968b, p. 147) designa de Estado educador, pois cria um novo tipo de civilização e conforma o indivíduo pela formação do consenso, onde a

Missão educativa e formativa do Estado, [...] é sempre
criar novos e mais elevados tipos de civilização, adequar
a "civilização" e a moralidade das mais amplas massas
populares às necessidades do desenvolvimento
continuado do aparelho econômico de produção, portanto
elaborar também fisicamente tipos novos de humanidade
(Ibidem, p. 91).

Esse Estado é composto de uma sociedade política que precisa da coerção para a manutenção da ordem, de uma função de dominação sobre as classes subordinadas, o que é realizado com o domínio direto por meio do judiciário e das forças militares, pela administração burocrática dos funcionários públicos e da política, ou seja, o executivo, o legislativo e o judiciário. Outra parcela que compõe o Estado, segundo Gramsci, é a sociedade civil: são os organismos privados, onde as classes antagônicas 
lutam para exercer e disseminar a hegemonia sobre a sociedade e, consequentemente, o domínio da ideologia. Nela se encontra a escola, professores, sindicalistas, jornalistas e igreja (Gramsci, 2004a), que interpretam normas conforme a concepção de mundo que vivenciam e em que acreditam.

O Estado geralmente utiliza o poder de forma coercitiva, combinada com o consenso passivo das classes subalternas, em prol de uma busca incessante de consolidação de domínio. O consenso passivo é formado principalmente pelos meios de comunicação; isso leva os grupos dominantes a buscarem o controle desses meios, de forma a manter a ordem social vigente. De acordo com SCHELESENER (2007b, p.3)

A base do sistema representativo moderno está na formação de opinião pública no seio da sociedade civil enquanto espaço de enfrentamento político; na sociedade capitalista o poder econômico pode determinar o processo de decisão agindo no âmbito da formação de opinião, [...] A desigualdade econômica torna a luta política desigual que debilita a participação das classes trabalhadoras no processo democrático burguês.

As classes subalternas podem se organizar por meio de uma sociedade civil organizada, livre e com consciência política desenvolvida, o que impede que apenas alguns poucos líderes o façam. Tal atitude cria a possibilidade de questionamento das relações capitalistas fundadas no mercado e no poder consolidado nas mãos de uma pequena parcela da população dominante. A partir desses pressupostos, pode-se elaborar uma nova concepção de mundo e uma nova prática política a serem repensadas e reconstruídas cotidianamente pela coletividade. A hegemonia, para as classes trabalhadoras, tem, como base, criar processos para a direção e a participação política da população de forma consciente e efetiva.

No contexto da concepção de GRAMSCI (2004a), a hegemonia tem vários sentidos, conforme os conflitos sociais, o modo de vivenciar a política e as relações de poder estabelecidas. Citam-se aqui ao menos três, que visam a esclarecer a situação política no contexto de um determinado modelo de Estado: 
a) Hegemonia enquanto correlação de forças entre sociedade política e sociedade civil.

[...] a supremacia de um grupo social manifesta-se de duas maneiras: como "domínio" e como "direção intelectual e moral". Um grupo social também é dominante dos grupos adversários que tende a "liquidar" ou a submeter também com a força armada, e é dirigente dos grupos afins e aliados. Um grupo social pode e deve ser dirigente já antes de conquistar o poder governativo (esta é uma das condições para a própria conquista do poder); depois, quando exerce o poder e mesmo se o tem fortemente na mão, torna-se dominante mas deve continuar a ser também "dirigente" (GRAMSCI, 1978a, p. 276).

A hegemonia se consolida como domínio e direção que precisam ser equilibrados no conjunto das forças que disputam o poder. Numa estrutura estatal conservadora como a do Piemonte, base dessa reflexão de Gramsci, as alianças políticas são fundamentais para consolidar o poder. Um aspecto importante da hegemonia como relação entre domínio e direção é que, nesse tipo de estrutura "a direção política torna-se um aspecto da função de domínio" e o grupo dirigente passa a empenhar-se na "absorção gradual mas contínua, obtida com métodos diversos na sua eficácia, dos elementos ativos saídos dos grupos aliados e também dos adversários" (GRAMSCI, 1978a, apud SCHELESENER, 2007c, p. 72).

b) A hegemonia no contexto de um Estado que se identifica com governo; nessa estrutura política ocorre a separação entre sociedade política e sociedade civil, o que

[...] significaria um Estado cujas funções limitam-se à tutela da ordem pública do respeito às leis. Não se insiste no fato de que nesta forma de regime (que além do mais só existiu, como hipótese limite, no papel) a direção do desenvolvimento histórico pertence às forças privadas, à sociedade civil, que é também "Estado", aliás o próprio Estado (GRAMSCI, 1968b, p. 148).

Esse tipo de hegemonia é largamente observável nos governos liberais, nos quais é preciso se utilizar do consenso passivo para atingir os objetivos e manter-se no poder, ou seja, para manter o seu domínio. Nesse processo, a população fica à margem das decisões, embora acredite 
participar por meio das eleições. As leis que deveriam servir para proteção exercem, na realidade, a função de controle e repressão. Nesse sentido, o Estado é tido como um guarda noturno.

c) A hegemonia na construção de relações democráticas (socialistas):

Entre os muitos significados de democracia, parece-me que o mais realista e concreto é aquele que se pode deduzir em conexão com o conceito de "hegemonia". No sistema hegemônico, existe democracia entre o grupo dirigente e os grupos dirigidos na medida em que o desenvolvimento da economia, e por conseguinte da legislação, que exprime este desenvolvimento, favorece a passagem (molecular) dos grupos dirigidos ao grupo dirigente (Ibidem, p.183).

Gramsci demonstra, por meio de seus escritos, que no dado conceito de hegemonia há uma valorização da sociedade civil e do processo de favorecimento da passagem de dirigidos a dirigentes. Há o preparo para uma autonomia, participação e organização a serem construídas e reconstruídas coletivamente, por meio de uma nova concepção de mundo, na qual, em vez de governantes, procuram-se formar dirigentes, na busca de uma socialização política de forma a ultrapassar divisão entre dirigentes e dirigidos.

É necessário, nesse sentido, questionar se há formas de preparar melhor esses dirigentes, ou se seria possível eliminar a divisão entre dirigentes e dirigidos, já que tal divisão é um fato histórico e faz parte da divisão de classes (Ibidem, p. 18, 19, 20).

O conceito de democracia operária utilizado por Gramsci é diferenciado da democracia na qual o mundo se insere: a democracia burguesa $^{1}$. Esta última tem como ideário o liberalismo, partindo de um modelo utópico, com a aparência de uma realidade social desigual, produzida pelo modo de produção capitalista. Nesse modelo há a crença da participação igualitária, principalmente com relação ao sufrágio universal,

\footnotetext{
1 De acordo com Schelesener (2002, p. 35), "No campo da democracia burguesa as eleições, o debate parlamentar (o parlamento é o lugar onde se 'parla'), a proclamação da igualdade de acesso aos direitos individuais e outras práticas ocultam a relação efetiva e o contato direto dos grupos econômicos com as instituições estatais, criando nas classes trabalhadoras a ilusão da participação igualitária e do exercício de uma política democrática no âmbito do Estado".
} 
priorizando a quantidade, sedimentando o senso comum ${ }^{2}$ e separando a esfera política da econômica. A democracia operária, segundo a visão gramsciana, deve operar com vistas ao aspecto qualitativo, destacando os limites da participação das classes menos favorecidas no interior dessa estrutura de sociedade capitalista.

A partir desta nova visão de mundo, de experiências colaborativas, o trabalhador, adquire condições de educar-se, de perceber as relações, os limites da democracia burguesa e o processo hegemônico, e proporcionando condições de se instaurar uma nova democracia, uma democracia operária que garanta a liberdade de todos e promova uma participação efetiva nas decisões, não apenas aceitando sem questionamentos as decisões dos dirigentes; ou seja, que a classe trabalhadora, deixe de se submeter à hegemonia da classe dominante, percebendo as relações de poder que estão interligadas a estas ações. Essas idéias são resultantes da experiência de Gramsci com os Conselhos de Fábrica, movimento pelo qual buscava a formação política dos trabalhadores das fábricas, relacionando produção, educação e política.

Nesta experiência com os conselhos, havia uma busca conjunta de deliberação frente aos problemas e compreensão das relações e estrutura de trabalho e de sistema. Os conselhos deveriam desencadear o desenvolvimento dos operários, levando-os a obter uma visão de toda a formação cultural, política e, consequentemente, a perceber os limites da democracia burguesa e a construir uma democracia operária (GRAMSCI, 2004a). Por meio desse trabalho, o operário adquiria possibilidades de refletir sobre sua ação, o que o levaria a construir uma nova concepção de mundo.

A democracia é importante na medida em que favorece a expressão política das massas; ela deve necessariamente atingi-las de uma maneira direta, por meio de um movimento político, ou seja, na busca de uma participação consciente, criativa, efetiva e revolucionária. É por meio de tal

\footnotetext{
${ }^{2}$ Para Gramsci (2004b, v.1, p. 77), o senso comum, "prega habitualmente que é melhor um ovo hoje do que uma galinha amanhã. E o senso comum é um terrível navio negreiro dos espíritos."
} 
organização política que os trabalhadores constroem um novo modo de pensar e agir; a união, portanto, o contexto e a realidade passam a ter um novo sentido.

Para GRAMSCI (2004a), todos deveriam participar igualmente das decisões e ter as mesmas chances de concorrer e vencer, isto é, de se tornar dirigentes. Nesse sentido, Gramsci contrapõe-se à visão de Michels, que parte da concepção de que a política é feita apenas por líderes carismáticos.

Gramsci aborda aspectos específicos da função intelectual. Esta é a do dirigente que exerce funções de dominação ou de direção cultural. Suas ações visam conservar relações de poder, mas podem também exercer a função crítica e transformadora.

Para as classes trabalhadoras, a formação de dirigentes críticos e participantes é essencial na sua luta pela hegemonia; dirigentes que desenvolvam uma nova concepção de mundo, crítica e coerente, de forma a compreender as contradições, criticando-as e superando-as (GRAMSCI, 1978b). Nas sociedades modernas, a luta hegemônica implica a conquista da direção cultural. Isso se depreende da escrita de Gramsci:

A distinção estabelecida entre domínio (momento da força) e direção (organização do consenso) é fundamental: o grupo dominante não se torna dirigente senão quando chega, por meio dos seus dirigentes, a exercer a sua hegemonia sobre a sociedade inteira (Ibidem, p.276).

Essa conquista hegemônica é um processo cultural e gradativo pelo qual uma classe social historicamente ascendente espalha valores de forma a modificar a concepção de mundo vigente, levando outras camadas da sociedade a aceitarem seu projeto político como único existente. Esse processo ocorre por meio dos dirigentes orgânicos e pela formação de um bloco histórico forte, que garanta um progresso intelectual das massas. Portanto, para GRAMSCI (2004a), há a necessidade de que um grupo seja dirigente, antes mesmo de alcançar o poder governamental, ou seja, que comande o bloco histórico vigente. 
É fundamental a participação dos dirigentes na compreensão das relações e contradições existentes na sociedade, com vistas a formar, nas classes trabalhadoras, um pensar autônomo e crítico.

Assim, ao revelar os mecanismos por meio dos quais as classes dominantes mantêm as relações de poder, Gramsci buscou criar subsídios para que as classes trabalhadoras questionassem e criassem seus próprios instrumentos de luta. Ele acreditava que primeiramente era necessária a conquista da cultura e da política, para que, mais tarde, após um amadurecimento, essas massas pudessem finalmente se tornar dominantes. Evidencia-se aí a necessidade de instituições para auxiliarem nessa formação.

A hegemonia é refletida como um processo cultural pelo qual uma classe social difunde valores e normas de forma a promover a mudança de uma determinada concepção de mundo; nesse sentido, ocorre a adesão de inúmeras parcelas da sociedade a sua concepção.

De acordo com essas reflexões, a hegemonia implica grupos sociais, choque de interesses, conflitos, correlação de forças e deveria ser um fundamento para um novo Estado proletário. Assim, a luta política para Gramsci é uma luta cultural, sem, no entanto, deixar de ser política e econômica.

Nesse processo se formam os valores, as concepções de mundo que mediatizam a vida da sociedade. Por meio da relação social promovida com a educação, que modifica o ambiente cultural e acentua o caráter político dessa ação, evidencia-se uma teoria a partir de uma participação política efetiva. Promove-se um pensar autônomo, elaborado a partir da prática cotidiana, uma nova visão de mundo, que é essencial para a compreensão da existência da realidade.

Para tanto, torna-se necessário o conhecimento do processo histórico-social pela classe subalterna com vistas a não só romper o senso comum e a fragmentação, mas também a estender a compreensão das relações em um nível filosófico. 
O projeto revolucionário de Gramsci apresenta um conteúdo econômico, político, ideológico e cultural que deve ser abordado a partir da luta de classes, contexto no qual os dirigentes têm um papel que é imprescindível: o de organização e orientação das massas, além de desvelar as relações de contradições existentes na sociedade para esclarecimento de uma concepção de mundo histórico-política e para manutenção ou superação de sua condição de classe dominada.

Os dirigentes desempenham uma função em conformidade com sua colocação no processo produtivo, em especial na sociedade moderna. Para que uma estrutura democrática exista de maneira efetiva, é primordial que se formem seres humanos livres, com capacidade de argumentação, discernimento e orientação.

Para Dias, intelectual ou dirigente

[...] é aquele que realiza o processo de reelaboração do pensamento estratégico e a resolução das questões coletivas colocados pela classe. Por isso, não pode haver cisão entre intelectual e classe nem postura hierárquica que constranja a classe que ele busca representar ou que de fato representa (2006, p.42-43).

As classes dominadas, para conquistar a hegemonia, precisam organizar-se politicamente e formar seus dirigentes. Os dirigentes desempenham um papel fundamental na concretização de um pensar autônomo e crítico das classes subalternas; isso favorece a teorização da prática e a apropriação da herança cultural reelaborada de acordo com um projeto político e revolucionário, que visa à melhoria e à superação das condições das classes populares.

Nesse sentido, a atuação do dirigente se dá como uma atividade inserida em um processo histórico e cultural, não de forma individualizada, mas coletiva ${ }^{3}$, com a finalidade de superar o senso comum, desenvolver a autoconsciência crítica e combater a ideologia posta. Para Gramsci (GRAMSCI, s/d), significa disseminar, de forma crítica, verdades

\footnotetext{
${ }^{3}$ Para Gramsci (2004b), as vontades coletivas só devem ser admitidas se tiverem uma finalidade universal concreta.
} 
conhecidas, torná-las públicas para todas as pessoas e convertê-las como imprescindíveis.

Portanto, de acordo com os escritos de GRAMSCI (s/d, p. 82, 83), este processo cultural não pode ser visto como um "saber enciclopédico" com dados desconexos, que sirva apenas para "criar um certo intelectualismo flácido e incolor". O homem é "criação histórica", que conquistou uma consciência pautada de uma reflexão inteligente "sobre as razões de certos fatos e sobre os meios considerados melhores para os converter de ocasião de vassalagem em insígnia de rebelião e de reconstrução social". Esses papéis desempenham uma penetração cultural em toda a classe, pois exigem uma educação permanente, contínua e comprometida com transformações.

GRAMSCI (1968a) defende que todos são dirigentes, pois possuem a capacidade de pensar e de se envolver; eles se confrontam com a natureza e a sociedade e produzem soluções para seus problemas, mesmo que seja a partir das tarefas mais simples, pois não existe atividade humana da qual se possa excluir a intervenção intelectual. Para ele, esses são os dirigentes os quais o partido precisa despertar e cuja consciência política precisa desenvolver pelos meios educacionais. A educação, para esse pensador, é a principal função do partido; a organização das massas não existe se não existirem dirigentes. De acordo com Broccoli,

[...] todos los hombres son portadores, ou sea, creadores, de 'condiciones similares'; pero ellos saben que sólo expresándose en una 'volutad??? colectiva' pueden modificar uma determinada realidad... el conformismo gramsciano es más que nada el resultado de una suma de actividades individuales que convergen hacia iguales finalidades, pero, como tal, no excluye el momento del individuo que se pone 'creativamente' frente a la historia, a la natureza, a su próprios iguales (1979, p.299-300).

Há a necessidade de uma contínua e permanente elaboração e experimentação da cultura, fundada em uma concepção histórica, por meio de uma organização que envolva os interesses coletivos das massas, que se paute pela compreensão histórica e individual do ambiente em que essas 
massas estão inseridas. Tal tarefa é realizada pelos dirigentes, na atividade de pensar, refletir, criticar e agir.

Acredita-se que, nesse processo, os dirigentes têm uma importante função, pois ocupam espaços de decisão e de formação política desses indivíduos na sociedade. A hegemonia, de acordo com Gramsci, só poderia ser construída no interior do partido com o estabelecimento de práticas de formação ideológicas de trabalhadores com propósitos firmes e bem instruídos, de formação de novos dirigentes.

A formação política, para GRAMSCI (2004b), é o elemento chave que agrega valores e retira as massas do senso comum; é o meio de transformar o indivíduo em ser histórico e ativo nesse processo que se dá coletivamente.

Com o processo de organização política das classes trabalhadoras, ocorre o envolvimento da sociedade civil e sua organização em instituições organizadas, vinculadas a um sistema estruturado; de acordo com GRAMSCI (2004b), o partido absorve e disciplina toda a classe trabalhadora, com vistas à conquista da hegemonia e da democracia, para proporcionar a formação/educação de homens solidários que se unam com os demais em busca de objetivos comuns.

\section{Cultura}

A cultura é “organização, disciplina interior", conhecimento de si, percepção de uma consciência superior, pelo qual se compreende seu valor histórico, a função da vida, os direitos e deveres (GRAMSCI, s/d). São visões que estão interligadas no entorno, que propiciam ao homem relacionar-se com a natureza pelo trabalho. São as revoluções e o desenvolvimento histórico global vivenciados por ele que o tornam fruto dessas relações. Portanto, o homem transforma-se e é transformado continuamente no decorrer de suas relações, necessárias e voluntárias, que são o "processo de seus atos” (GRAMSCI, 2004a). 
Em uma nota intitulada Retorno De Sanctis, escrita em meados de 1934, em um dos últimos escritos carcerários, GRAMSCI (2004a, v.6, C.23 p.63 - 64) começa a reproduzir uma idéia do filósofo e historiador da literatura italiana Francesco De Sanctis, segundo a qual a cultura significa

[...] uma coerente, unitária e nacionalmente difundida concepção da vida e do homem, uma religião laica, uma filosofia que tenha se transformado precisamente em cultura, isto é, que tenha gerado uma ética, um modo de viver, uma conduta civil e individual.

Dessa forma, a cultura é um bem universal que inclui as dimensões política e econômica da sociedade; ela é considerada unitária quando proporciona a compreensão das relações contraditórias da realidade, com vistas a criticá-las e superá-las. A cultura é, entretanto, percebida por Gramsci como sendo dirigida por uma elite, numa estrutura hierarquicamente montada e permeando o senso comum de grande parte da população. Nesses termos, o que se torna importante é permitir uma formação do indivíduo por meio de uma reforma cultural, em que uma das possibilidades de sua efetivação seria a partir da organização política dos trabalhadores, relacionando teoria e prática.

No sentido gramsciano, a cultura produzida e reproduzida por meio da organização política deve ser passada para as gerações futuras, como ideal educativo, pois é um modo de perceber a realidade por um povo. Um modo de vida inserido na sociedade que internamente proporciona uma luta entre os diferentes projetos políticos que objetivam a condução da sociedade e permite um movimento de formação de classe. É uma função estratégica da política na perspectiva de tornar uma classe hegemônica.

A esse propósito, para GRAMSCI (2004a), criar uma nova cultura significa propagar verdades já existentes e socializá-las, a fim de torná-las a base para atuações conscientes e críticas. Assim segue o pensamento dele:

[...] a filosofia da práxis não tende a resolver pacificamente as contradições existentes na história e na sociedade, mas é a própria história de tais contradições; não é o governo de grupos dominantes para ter o consenso e exercer a hegemonia sobre as classes subalternas; mas é a expressão destas classes que querem 
educar a si mesmas para a arte do governo e têm interesse em conhecer todas as verdades, também as desagradáveis, e evitar os enganos (impossíveis) da classe superior e até de si mesma (ibidem, p.388).

Dessa forma, retoma-se o pensamento historicamente produzido e reinterpreta-se considerando novas determinações sociais, o que implica pensar a teoria na relação com a prática, vinculando, de maneira inseparável, prática política, formação, luta cultural e conhecimento histórico, sem deixar-se influenciar pelas idéias de uma minoria que se utiliza dessa cultura para manter a hegemonia.

Pode haver reforma cultural, elevação civil das camadas mais baixas da sociedade, sem uma precedente reforma econômica e uma modificação na posição social e no mundo econômico? Eis por que uma reforma intelectual e moral não pode deixar de estar ligada a um programa de reforma econômica. E mais, o programa da reforma econômica é exatamente o modo concreto através do qual se apresenta toda reforma intelectual e moral (GRAMSCI, 1968b, p. 9).

Na realidade social e política uma instância depende da outra para que a formação objetive uma participação política consciente e efetiva. $\mathrm{Ou}$ seja, uma reforma cultural está intrinsecamente interligada a uma reforma moral e consequentemente a uma reforma econômica. Sem a reforma econômica não se criam condições para que as demais se realizem; portanto há uma relação entre o sentido da política, da economia e da cultura, que é expresso da seguinte forma: a política, a economia e a cultura são instâncias que interagem dialeticamente.

É a compreensão de que o indivíduo está imerso em uma série de fatores que, tratados isoladamente, não deixam transparecer a noção real do que essas relações representam. Esse indivíduo deve adquirir a consciência de que é parte de um conjunto histórico e social, além de compreender a situação em que está inserido, com a finalidade de construir uma nova cultura e promover a organização das classes.

GRAMSCI (2004b) defende que é dever do partido elevar o nível cultural de seus membros; a consciência de toda a classe só se modificará quando se modificar o seu modo de vida, por meio da organização política e 
do estímulo do pensamento e da ação, da promoção de uma discussão em comum, objetivando modificar consciências, conquistar uma nova hegemonia e promover a superação da divisão entre governantes e governados, entre dirigentes e dirigidos.

Para Gramsci é imprescindível que as classes dominadas se movam e se organizem com vistas a conquistar uma hegemonia intelectual e moral, que participem efetivamente das discussões nos processos decisórios. Isso implica participação política e educação ao longo da vida para superação dessa condição posta historicamente.

Dessa forma, a participação e a ação transformadora da escola para esclarecer como se dão os problemas sociais e as relações que são estabelecidas a partir de determinadas posições são essenciais para a constituição da consciência política, bem como a formação de professores para tal tarefa, que também pertence a esses profissionais.

Assim, "participar é dar parte e ter parte” (FERREIRA, 2001, p.51), pois a educação é uma manifestação própria do ser humano, sendo que o homem precisa produzir a sua própria existência de maneira contínua.

Essas relações que se fazem no interior da escola podem auxiliar no processo de formação política, funcionando como uma inserção no mundo da participação e na busca constante por direitos e acesso a bens culturais e materiais. A gestão da escola, compartilhada por toda a comunidade educativa, funciona como esclarecedora desses processos que ocorrem na sociedade e como formadora de opiniões, objetivando desvelar as relações de poder instituídas na sociedade, além de formar o hábito de participar nas decisões.

\section{Referências bibliográficas}

BROCCOLI, A. Antonio Gramsci e la Educación como Hegemonia. 2 ed. México: Nova Imagen, 1979.343 p.

DIAS, E. F. Compreender o real, demonstrar sua inteligibilidade. IN: SCHLESENER, A. PANSARDI, M. (orgs). Políticas Públicas e Gestão da Educação. Coleção Cadernos de Pesquisa, v. 2. Curitiba: UTP, 2006. 192p. 
FERREIRA, N. C. (org). Gestão da Educaşão: impasses, perspectivas e compromissos. $2^{a}$ ed, São Paulo: Cortez, 2001. 320p.

GRAMSCI, A. Cadernos do Cárcere. Volumes 1, 2, 3, 4, 5, 6. Tradução: Carlos Nelson Coutinho. $3^{a}$ ed, Rio de Janeiro: Civilização Brasileira, 2004a. 408p.

GRAMSCI, A. Os Dirigentes e a Organização da Cultura. Rio de Janeiro: Civilização Brasileira, 1968a. 258 p.

GRAMSCI, A. Democracia Operária. Disponível em: http://www.marxists.org/portugues/gramsci/1919/06/21.htm. Acesso em 08 fev. 2008. 1p.

GRAMSCI, A. Escritos Políticos. V.1 e 2. Tradução: Carlos Nelson Coutinho. Rio de Janeiro: Civilização Brasileira, 2004b. 375 p.

GRAMSCI, A. Escritos Politicos, Lisboa: Seara Nova, s/d. 375p.

GRAMSCI, A. Maquiavel A Política e o Estado Moderno. Rio de Janeiro: Civilização Brasileira, 1968b. 444p.

GRAMSCI, A. Obras Escolbidas. São Paulo: Martins Fontes, 1978ª 421p.

GRAMSCI, A. Concep̧̧ão Dialética da História. Rio de Janeiro: Civilização Brasileira, 1978b. 341p.

GENTILI, P. et. al. Pedagogia da Exclusão. $3^{\text {a }}$ ed, Petrópolis: Vozes, 1997. 303p.

SCHLESENER, A. A Crítica de Gramsci à Teoria das Elites: Pareto, Mosca e Michels e a Democracia Burguesa. Disponível em: www.unicamp.br/cemarx/anais $\mathrm{v}$ coloquio arquivos/arquivos/comunicaçõe s/gt1/sessao4/Anita Shlesener.pdf, 2007b. Acesso em: 08 fev. 2008. 16 p.

WEFFORT, F. Qual Democracia? 2aed. São Paulo: Cia das Letras, 1996. 165 p. 